\title{
PREVALENCE AND INCIDENCE OF PRESSURE SORES IN ACUTE SPINAL CORD INJURIES
}

\author{
By Robert R. Richardson, M.D. and Paul R. Meyer, Jr., M.D. \\ Midwest Regional Spinal Cord Injury Care Center, Acute Spinal Cord Injury Unit; North- \\ western Memorial Hospital, Departments of Orthopaedic Surgery and Surgery, Division of \\ Neuro-Surgery; Northwestern University Medical School Chicago, Illinois 606I I
}

Key words: Acute spinal cord injury; Pressure sores.

\section{Introduction}

PRESSURE sores are the first or second most common problem following complete or incomplete physiological spinal cord injuries. But there are inadequate statistics available relating to the actual prevalence of pressure sores in acutely injured spinal cord patients, also regarding the prevalence of pressure sores relevant to to the different anatomical levels of spinal cord injury. Past statistics, which were compiled by Munro (I940), Poer (1946) and Kuhn (1947), are 30 years old and do not reflect the modern acute spinal cord injury centre data. Our purposes were not only to provide actual statistics relating to the prevalence of pressure sore development in acutely injured spinal cord patients during the initial hospital stay, but also to identify major factors involved in the development of pressure sores. Our statistical work was a retrospective study of 549 spinal cord injuries who were admitted to the Acute Spinal Cord Unit of Northwestern Memorial Hospital (Midwest Regional Spinal Cord Injury Center). The prevalence of pressure sores was calculated on a system versus a non-system entry, the physiological 'intactness' of the injury, the anatomical levels of injury, the presence of pressure sores upon admission or development during system stay, and the development of multiple and single pressure sores at specific sites.

\section{Materials and Methodology}

All patients entering the Midwest Regional Spinal Cord Injury Care System from I973 until June 1978 were included in this retrospective, computerised study involving the development of pressure sores (Table I). The patients were classified as either 'system' or 'non-system' patients. Non-system patients were those patients who entered the system (acute phase of injury at Northwestern Hospital Acute Spinal Cord Unit; chronic phase at the Rehabilitation Institute of Chicago) 72 hours or more from the time of injury. System patients entered less than 72 hours from the time of injury (Table I). All pressure sores were counted and included in this retrospective study. No distinction was made between Grades I to IV based on the classification system of Shea (I975).

The prevalence of pressure sores was based upon the division of system versus non-system entry, the development of pressure sores upon admission and/ or during system stay, by physiological intactness of the spinal cord injury (com-

Information and Reprints requested from: Paul R. Meyer, Jr., M.D., Room 6I9, 250 East Superior Street, Chicago, Il 606 I I, U.S.A. 


\section{TABLE I}

Distribution of spinal cord injuries (Midwest Regional Spinal Cord Injury Center, Northwestern Memorial Hospital, 1973-78)

\begin{tabular}{|c|c|c|c|c|}
\hline & Cervical & Thoracic & Lumbar & $\begin{array}{l}\text { Total } \\
\text { number }\end{array}$ \\
\hline $\begin{array}{l}\text { System complete } \\
\text { Non-system complete }\end{array}$ & $\begin{array}{l}61 \\
64\end{array}$ & $\begin{array}{r}53 \\
103\end{array}$ & $\begin{array}{r}8 \\
13\end{array}$ & $\begin{array}{l}122 \\
180\end{array}$ \\
\hline $\begin{array}{l}\text { TOTAL complete } \\
\text { Percentage of complete injuries by } \\
\text { anatomical region }\end{array}$ & $\begin{array}{l}\text { I25 } \\
(46)\end{array}$ & $\begin{array}{l}156 \\
(74)\end{array}$ & $\begin{array}{l}2 \mathrm{I} \\
(3 \mathrm{I})\end{array}$ & 302 \\
\hline $\begin{array}{l}\text { System incomplete } \\
\text { Non-system incomplete }\end{array}$ & $\begin{array}{l}56 \\
88\end{array}$ & $\begin{array}{l}21 \\
35\end{array}$ & $\begin{array}{l}20 \\
27\end{array}$ & $\begin{array}{r}97 \\
150\end{array}$ \\
\hline $\begin{array}{l}\text { TOTAL incomplete } \\
\text { Percentage of incomplete injuries by } \\
\text { anatomical region }\end{array}$ & $\begin{array}{l}\text { I44 } \\
(54)\end{array}$ & $\begin{array}{l}56 \\
(26)\end{array}$ & $\begin{array}{c}47 \\
(69)\end{array}$ & $\begin{array}{l}247 \\
-\end{array}$ \\
\hline $\begin{array}{l}\text { Totals by anatomical region } \\
\text { Percentage by anatomical region }\end{array}$ & $\begin{array}{l}269 \\
(49 \cdot 0)\end{array}$ & $\begin{array}{l}212 \\
(38 \cdot 6)\end{array}$ & $\begin{array}{c}68 \\
(12 \cdot 4)\end{array}$ & $\underline{549}$ \\
\hline
\end{tabular}

plete versus incomplete), and by the anatomical level of injury (cervical, thoracic and lumbar) (Table II). The prevalence of pressure sores was further subdivided by specific anatomical locations (gluteal-sacral sores, trochanteric-ischial sores, and all other sites) and by number of pressure sores (multiple meaning 'more than one' versus one specific site). Percentages of pressure sores in each specific anatomical and numerical subdivision to the total number of pressure sores in each category (anatomical location, physiological intactness of injury, system versus non-system) were calculated (Tables III, IV and V).

For non-system patients who were admitted into the system having previously

\section{TABLE II}

Prevalence of pressure sores in spinal cord injuries (Midwest Regional Spinal Cord Injury Center, Northwestern Memorial Hospital, I973-78)

\begin{tabular}{|c|c|c|c|c|c|c|c|}
\hline & \multicolumn{3}{|c|}{ System } & \multicolumn{3}{|c|}{ Non-system } & \multirow[b]{2}{*}{$\begin{array}{c}\text { Total } \\
\text { \# by } \\
\text { category }\end{array}$} \\
\hline & $\begin{array}{c}\text { Upon } \\
\text { admission }\end{array}$ & $\begin{array}{l}\text { During } \\
\text { system } \\
\text { stay }\end{array}$ & $\begin{array}{c}\text { Overall } \\
\text { prevalence }\end{array}$ & $\begin{array}{c}\text { Upon } \\
\text { admission }\end{array}$ & $\begin{array}{c}\text { During } \\
\text { system } \\
\text { stay }\end{array}$ & $\begin{array}{c}\text { Overall } \\
\text { prevalence }\end{array}$ & \\
\hline Cervical complete & 0 & 33 & $(54 \cdot \mathrm{I})$ & 34 & 8 & $(65 \cdot 6)$ & 75 \\
\hline Cervical incomplete & 0 & I9 & $(33.9)$ & 32 & 9 & $(46 \cdot 6)$ & 60 \\
\hline Thoracic complete & 0 & I9 & $(35 \cdot 9)$ & 46 & I 7 & $(6 I \cdot 2)$ & 82 \\
\hline Thoracic incomplete & 0 & 4 & $(19 \cdot 0)$ & 9 & I & $(28 \cdot 6)$ & I4 \\
\hline Lumbar complete & 0 & I & $(12 \cdot 5)$ & 6 & 3 & $(69 \cdot 2)$ & IO \\
\hline Lumbar incomplete & 0 & 5 & $\left(25^{\circ} 0\right)$ & 7 & 4 & $(40 \cdot 7)$ & I6 \\
\hline Total Number & 0 & $8 I$ & - & I34 & 42 & - & - \\
\hline
\end{tabular}

( ) Indicates percentage. 


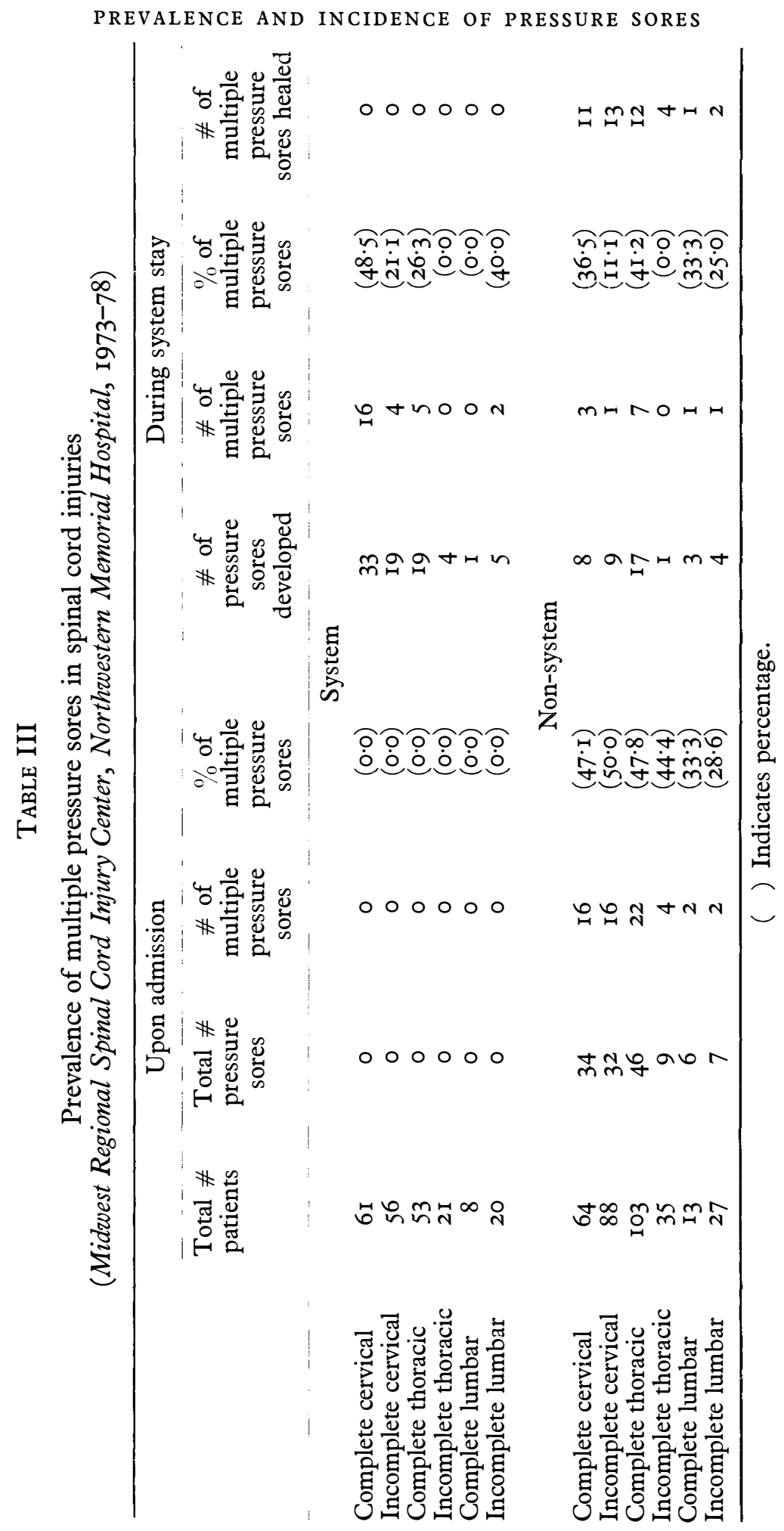




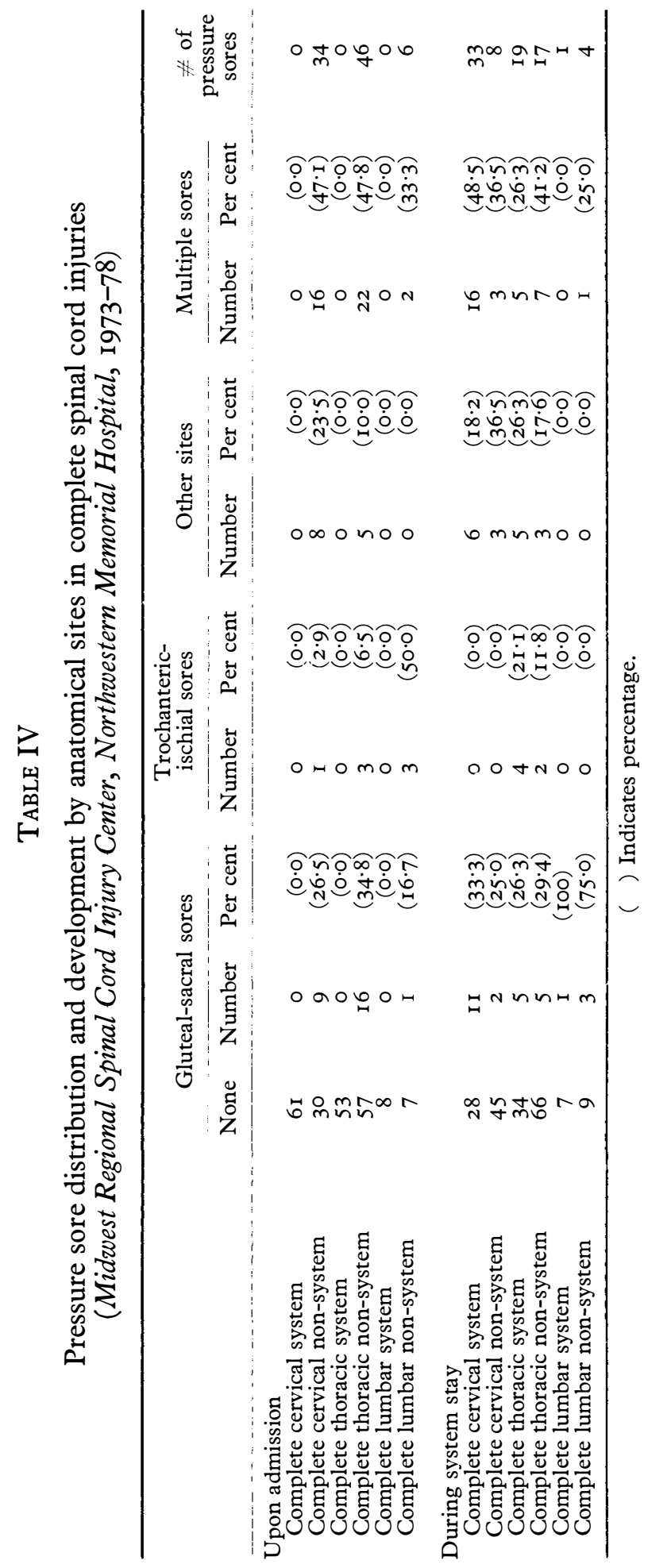


PREVALENCE AND INCIDENCE OF PRESSURE SORES

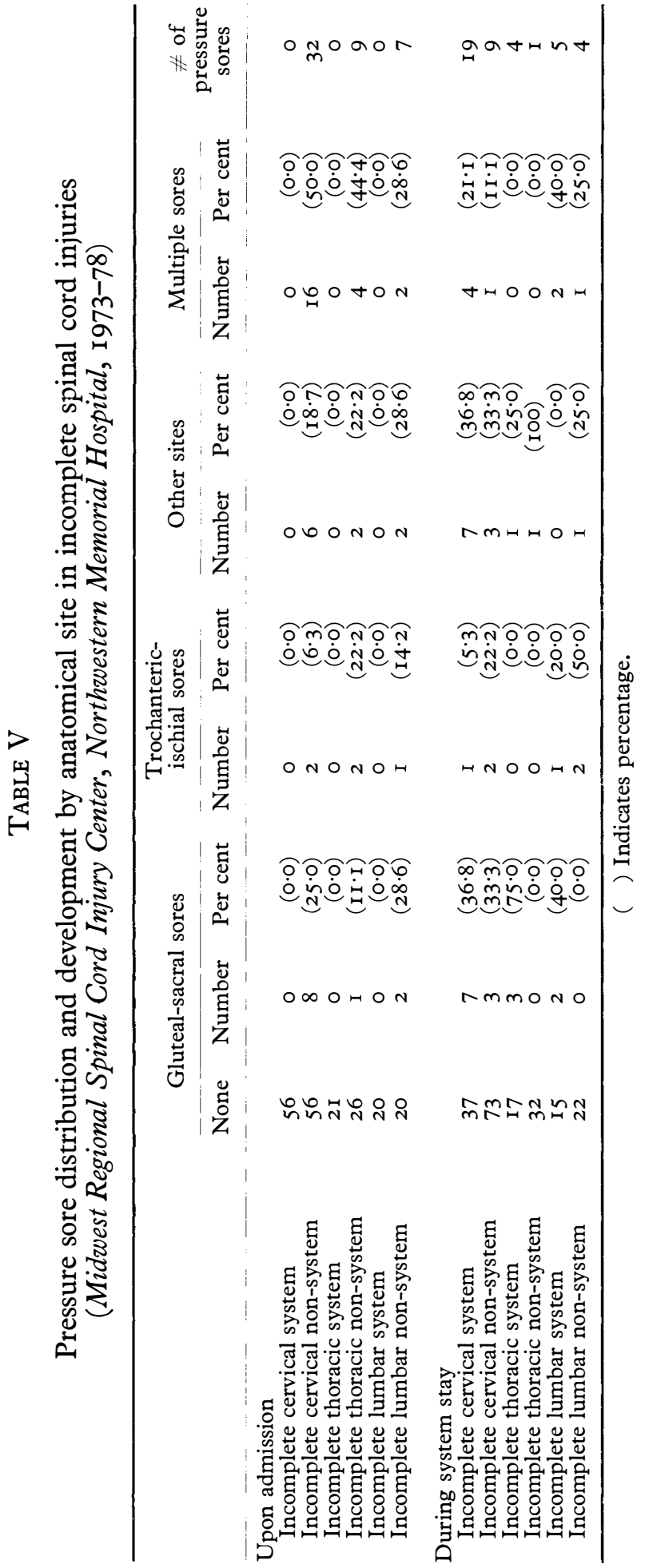




\section{TABLE VI}

Pressure sore distribution and course during system stay for nonsystem (admission) complete and incomplete spinal cord injuries

(Midwest Regional Spinal Cord Injury Center,

Northwestern Memorial Hospital, I973-78)

Complete cervical Incomplete cervical Complete thoracic Incomplete thoracic Complete lumbar Incomplete lumbar
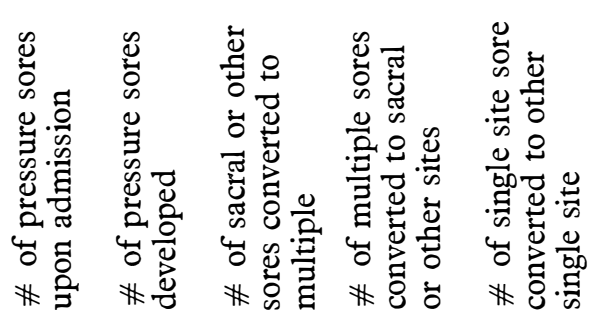

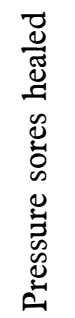
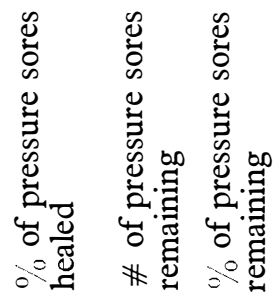

$\begin{array}{rr}34 & 8 \\ 32 & 9 \\ 46 & 17 \\ 9 & 1 \\ 6 & 3 \\ 7 & 4\end{array}$

$\begin{array}{ll}5 & 4 \\ 2 & 2 \\ 8 & 5 \\ 0 & 1 \\ \text { I } & 0 \\ 0 & \text { I }\end{array}$

$\begin{array}{rlll}22 & (64 \cdot 7) & \circ & (35 \cdot 3) \\ 26 & (8 \mathrm{I} \cdot 3) & \mathrm{I} & (\mathrm{I} 8 \cdot 7) \\ 25 & (54 \cdot 3) & 2 & (45 \cdot 7) \\ 7 & (77 \cdot 8) & 0 & (\mathbf{2 2} \cdot 2) \\ 5 & (88 \cdot 3) & 0 & (\mathrm{I} \mathrm{I} \cdot 7) \\ 6 & (85 \cdot 7) & 0 & (\mathrm{I} 4 \cdot 3)\end{array}$

Indicates percentage.

developed pressure sores, the prevalence of pressure sores in numbers and percentages were calculated for healing and non-healing, for conversion to other single sites, and for conversion from multiple sites to a single site during the acute system stay (Table VI).

\section{Discussion}

One of the most common problems following complete or incomplete physiological spinal cord injuries is pressure sores or pressure ulcers. Dowling (I970) and Ruge (1969) have stated that 'pressure sore' is a better term than 'decubitus ulcer' since 'decubitus' means 'lying down'. Other terms such as bed sores (Munro, I940) and ischaemic ulcers (Kosiak, 1959) have been used, but these are now considered inappropriate. Dowling (1970) and Talbot (1968) stated that the pressure sores of patients with cervical cord injuries differ anatomically from those with thoracic and lumbosacral cord injuries, since patients with the latter injuries are able to sit and to get around in wheelchairs for prolonged periods of time.

There are few statistics available in the medical literature that pertain to the actual prevalence of pressure sores in spinal cord injured patients. Guttmann, mentioned by Kuhn (I947) and by Ruge (I969), stated that 85 per cent of spinal cord injured patients had pressure sores on admission to the Spinal Injuries Centre at Stoke Mandeville Hospital. Dietrick and Russi (1958) found a prevalence of 68.6 per cent of pressure sores in the autopsy findings of 55 paraplegics. In an analysis of spinal cord injured vererans of World War II, Kennedy (1946) found that over 75 per cent had developed pressure sores. Poer (I946) found that $57^{\circ} \mathrm{I}$ per cent of these wartime casualties had pressure sores upon admission to a veterans hospital. Poer (I946) also discovered that over 70 per cent of these 
casualties with pressure sores had multiple pressure sores. Munro (1940) found an incidence of 28 per cent among civilian spinal cord injury patients developing pressure sores. Even though his statistics were collected over 30 years ago, Munro's statistics (1940) were the only previous values that were categorised into anatomical levels of injury: cervical, thoracolumbar and cauda equina injuries. In his analysis of I 26 patients with spinal cord injuries, Munro (I940) calculated the percentage of pressure sores according to the anatomical level of injury as follows:

I. Cervical cord injury: 76 cases, I3 cases having pressure sores, or about 20 per cent.

2. Thoracolumbar cord injury: 26 cases, I4 cases having pressure sores, or 54 per cent.

3. Cauda equina injury: 24 cases, three cases showing pressure sores, or I 2 per cent.

4. Combined cervical and cauda equina injuries: Ioo cases, I6 cases having pressure sores, or approximately I 8 per cent.

But his values included both initial hospitalisation for traumatic spinal cord injuries and readmission for chronic or secondary problems, such as the development of pressure sores.

The sites at which pressure sores occur have been classically described as being those cutaneous sites overlying osseous prominences. With a cervical cord injury, with the patient being in a lying position primarily during the acute phase of the injury, the sites where pressure sores most frequently occur are, according to Campbell (1946) and Dowling (1970), the skin over the sacrum, greater trochanters, patellae, malleoli, anterior iliac spines, heels, ribs and the vertebral spinous processes. With thoracic and lumbosacral cord injuries patients are more frequently in a sitting position, and Kuhn (1947) and Dowling (1970) found the sites of involvement are primarily the ischial tuberosities and the sacro-coccyxgeal regions. Munro (I940) stated that pressure sores were primarily sacral in lcoation.

A multitude of aetiological factors have been ascribed to the development of pressure sores in spinal cord injured patients. Talbot (I968) and Dowling (1970) stated that these include anaemia, malnutrition, hypoproteinaemia, chronic or systemic infection, poor hygiene, immobility, the preservation or absence of sensation and the presence of spasticity. Kosiak (1959) and Mikulk (I977) found that local circulatory disturbances and interruption of vasomotor pathways due to autonomic dysfunction were also causative factors. But the major constant factor associated with their appearance and persistence is pressure. Various authors consider that the 'physiological completeness' or 'incompleteness' of the spinal cord injury is also a prime factor in the development and persistence of pressure sores. Our values show that pressure sores are substantially more frequent in complete than in incomplete injuries, except for the complete lumbar system category. This figure is probably not relevant because only eight patients were in this category.

With the establishment of major acute spinal cord injury centres in the United States, the concept of 'system' versus 'non-system' also has to be taken into account. The significantly higher prevalence of pressure sores in nonsystem patients, as compared to system patients, resulted from a substantial difference in transportation and nursing and medical care. Specialised, rapid transportation of acute spinal cord injuries and the availability of highly professional, specialised nursing staff played a major role in the less frequent development 
of pressure sores in system patients, especially on admission. In addition, of the pressure sores that non-system patients possessed at the time of hospitalisation and entry in the Acute Spinal Cord Injury Centre (System), over 70 per cent of these healed. If multiple pressure sores existed on admission, the majority healed or converted to other single sites. These statistics can only be indicative of the superior nursing care that was provided by a specialised acute spinal cord injury centre.

In comparison to Munro's statistics (1940), our figures show that the overall prevalence of pressure sores was highest in complete cervical cord injuries $\left(54^{\circ} \mathrm{I}\right.$ per cent) in system patients; 65.6 per cent in non-system patients, with complete thoracic cord injuries being second in frequency $\left(35^{\circ} 9\right.$ per cent in system patients; 6I.2 per cent in non-system patients). While in Munro's series, pressure sores were primarily located in the sacral region, more than 50 per cent of our complete cervical cord injury patients developed pressure sores had multiple sites of occurrence. The reason for our higher statistics in complete cervical cord injuries, as well as the multiple sites of pressure sores of occurrence, are related to the association of multiple systemic injuries. Over 50 per cent of the incomplete and complete system cervical cord injury patients had serious associated traumatic injuries (Richardson and Meyer, unpublished data). The significant relationship could also explain the greater number of pressure sores that developed during hospitalization of system-entry patients compaired to non-system entry patients. In other words, the cutaneous system was always superceded by the central nervous (brain), cardiorespiratory, gastrointestinal, genitourinary and the musculoskeletal systems in these multiple, systemic trauma patients. With appropriate surgical and medical treatments and stabilisation of these other systems, the cutaneous system was then cared for.

The significance of pressure sore development following acute spinal cord injury is not only relevant for medical reasons, but also for economic ones. Edberg (I973) estimated that the cost of treating a spinal cord injury patient for a single pressure sore is approximately $\$ 15,000$. With the continuing yearly increases in the expense of hospitalisation and inflation, a present cost analysis would probably double Edberg's figures.

\section{Results}

\section{Anatomical location of prevalence of pressure sores by category}

The overall prevalence of pressure sores following spinal cord injury was highest in the cervical complete category for both system and non-system patients, $54^{\circ}$ I per cent and $65^{\circ} 6$ per cent, respectively (Table II). The second category in order of frequency for both system and non-system patients, 35.9 per cent and $6 \mathrm{I} \cdot 2$ per cent respectively, was thoracic complete (Table II). This category was followed by cervical incomplete lesions for both system and non-system patients, 33.9 per cent and 46.6 per cent respectively (Table II). The lumbar complete and incomplete categories had the lowest incidence of pressure sores, but they also had the smallest number of patients (Tables I and II). Calculating the overall prevalence of pressure sores by the number of quadriplegic (cervical complete in both system and non-system) patients, the atcual incidence was 60 per cent ( 75 pressure sores in 125 quadriplegic patients) in quadriplegics, to 52 per cent (92 pressure sores in 178 paraplegic patients) in paraplegics (Tables I and II). Applying similar calculations to 'incomplete quadriplegics' and 'incomplete paraplegics', the values are 42 per cent (60 pressure sores in 144 incomplete 
cervical patients) for the former, and 29 per cent ( 30 pressure sores in I03 incomplete thoracic and lumbar patients) for the latter (Tables I and II).

\section{Prevalence of pressure sores in system vs. non-system patients}

The overall prevalence of pressure sores in all six categories was significantly greater in non-system than system patients. The percentages varied from a difference of approximately nine in the thoracic incomplete category to approximately 57 in the lumbar complete category (Table II).

Upon admission, no pressure sores were identified in any category in system patients. During the system hospitalisation, system patients developed a total of 8I pressure sores (Table II). Non-system patients had I34 pressure sores upon admission into the system and developed 42 'new' pressure sores during the system stay (Table II).

Prevalence of pressure sores based upon the physiological intactness of the spinal cord

In both system and non-system patients, cervical and thoracic incomplete categories had a significantly lower prevalence of pressure sores than the cervical and thoracic complete categories (Table II). For the cervical region, the overall percentages in both patient groups were 19 to 20 percentage points lower in the incomplete injuries than complete injuries (Table II). For the thoracic region, the incomplete versus the complete values were I9 per cent and $35^{\circ} 9$ per cent, respectively, in the system patients; and 28.6 per cent and $6 \mathrm{I} \cdot 2$ per cent, respectively, in the non-system patients (Table II). The exception occurred in the lumbar region in system patients where the lumbar complete showed a prevalence of 12.5 per cent of pressure sore development while the lumbar incomplete showed 25 per cent (Table II). In lumbar non-system patients, the values were 69.2 per cent in the complete group, to 40.7 per cent in the incomplete group, which correlates with the findings in the cervical and thoracic regions (Table II).

\section{Prevalence of multiple pressure sores}

The highest prevalence of multiple pressure sore development in acute spinal cord injured patients developing pressure sores was found in the system complete cervical (48.5 per cent) and complete thoracic ( 26.3 per cent); and in the nonsystem complete cervical $(36 \cdot 5$ per cent) and complete thoracic ( $4 \mathrm{I} \cdot 2$ per cent) categories (Table III). While the system lumbar incomplete group showed a 40 per cent value, and the non-system lumbar complete group showed a 33.3 per cent value, both groups had small total numbers of patients ( 20 and 13 patients, respectively) (Table III).

\section{Specific single anatomical sites favouring pressure sore development}

Next to multiple pressure sores, the most frequent single site for pressure sore development in both system and non-system complete cervical categories was the gluteal-sacral region. The values varied from 25 per cent to 33.3 per cent (Table IV). Following the development of pressure sores at multiple sites in incomplete cervical injuries, the gluteal-sacral region was the second most common site for the development of pressure sores in both system and non-system patients (Table V). In both system and non-system complete thoracic and complete lumbar categories, the propensity of the sacral-gluteal region for the development of pressure sores is significant. But the sacral-gluteal region for the thoracic categories remains numerically secondary to the development of pressure sores 
at multiple sites, except for the incomplete thoracic non-system category where trochanteric ischial sores and pressure sores at other sites were more frequent (Tables IV and V). In both system and non-system patients for the complete and incomplete cervical and thoracic categories, except incomplete thoracic nonsystem, other sites (including back, foot, ankle, tibial region, malleolus, elbow or penile and scrotal regions) showed a higher prevalence of pressure sores than the trochanteric-ischial region (Tables IV and V). For system and non-system lumbar complete and incomplete categories, the percentage values of distribution of pressure sores could be misleading because of the small number of patients in these categories (Tables IV and V).

\section{Prevalence of pressure sores healing and remaining in non-system patients}

Since only non-system patients had pressure sores at the time of admission into the system hospitalisation, the course of these pressure sores regarding healing, conversion to multiple sites or conversion to other single sites appeared significant. Substantial healing of pressure sores upon admission occurred in all non-system patients (Table VI). These figures varied from 54.3 per cent in the complete thoracic category to 88.3 per cent in the complete lumbar category. For the remaining non-system patients with pressure sores, which varied from II 7 per cent in the complete lumbar category to $45 \cdot 7$ per cent in the complete thoracic category, the second most common course, except for the complete thoracic category, was the conversion of pressure sores at multiple sites to one specific site (sacral and other sites). Only in the complete thoracic category was the converse (conversion of pressure sores at single sites to multiple sites) apparent (Table VI).

\section{Calculation of incidence of pressure sore development in acute spinal cord injuries}

Incidence values, which shall be defined as the number of new (or future) acute spinal cord injured patients who will develop pressure sores, can be estimated from the data in Tables I to VI.

(a) Approximately 60 per cent of complete cervical cord injuries will develop pressure sores. Approximately 50 per cent of the complete cervical cord patients developing pressure sores will have multiple pressure sores, and about 25 per cent of those injuries will have a single pressure sore in the sacral-gluteal region.

(b) Approximately 40 per cent of incomplete cervical cord injuries will develop pressure sores of which less than one-half of these will be multiple, and more than 30 per cent of these patients will have a single pressure sore in the sacral-gluteal region.

(c) More than 50 per cent of paraplegics (complete thoracic and lumbar cord injuries) will develop pressure sores. Approximately 40 per cent of these paraplegics developing pressure sores will have them at multiple sites, and approximately 30 per cent will have one pressure sore in the sacralgluteal region.

(d) Less than 30 per cent of incomplete thoracic and lumbar cord injuries will develop pressure sores. These incomplete injuries developing pressure sores will generally develop a single pressure sore that will be located either in the sacral-gluteal or trochanteric-ischial regions, or at another site.

(e) In non-system patients, the vast majority (about 75 per cent) of patients 
developing pressure sores will have them at the time of admission into the system hospitalisation. Approximately 80 per cent of these pressure sores will be healed or will be found at another single specific site at the time of discharge from the acute system hospitalisation.

\section{Conclusions}

I. The overall prevalence of pressure sores is greater in non-system than in system patients in all six categories, varying from a minimal 9.6 percentage difference (thoracic incomplete) to a maximal 49.7 percentage difference (lumbar complete).

2. In variance to the earlier statistics of Munro (1940), our highest prevalence of pressure sores developed in complete cervical cord injuries instead of thoracic or thoracolumbar cord injuries. Both Munro's and our findings correlate that the most common site of single pressure sore development is sacral. Multiple pressure sores in cervical cord injured patients are more frequent than pressure sores at a single site.

3. Calculated values showed that quadriplegics were more prone to develop pressure sores at a single site and at multiple sites than paraplegics.

4. The fact that system entry patients develop more pressure sores during the acute phase of hospitalisation than non-system entry patients is related to the associated medical and systemic trauma (over 50 per cent of system complete and incomplete cord injuries had multiple-system trauma upon admission). In the presence of multiple systemic trauma, the cutaneous system took last place.

5. The excellence and competence of a specialised nursing and paramedical staff is attested to by the fact that over 70 per cent of non-system patients who had pressure sores upon admission had healing or conversion of the pressure sores from multiple sites to a different single site.

6. The rapidity and the competence of the system transportation system in transporting acute spinal cord injuries is attested by the fact that no system patient had a pressure sore upon admission.

7. Cost analysis for the treatment of a single pressure sore, based upon Edberg's I973 statistics, is approximately $\$$ I 5,000. With inflation and the cost of increased hospitalisation taken into account for a present cost analysis, the present figures would undoubtedly be double the I973 figure.

\section{SUMMARY}

The prevalence of pressure sores following acute spinal cord injury was determined on 549 patients who entered the Midwest Regional Spinal Cord Injury Care Centre from 1973 until June 1978. The compiled data was based upon system versus non-system entry, anatomical levels of injury, multiple site or single site location, complete or incomplete physiological injury, and the presence of pressure sores on admission or their development during system hospitalisation. The results showed that non-system patients had a significantly higher prevalence of pressure sores in all categories. The level of anatomical injury as well as the physiological intactness of the spinal cord were found to be the most important factors in the actual prevalence. The cervical region was found to have the highest prevalence of pressure sores at single and multiple sites. Complete lesions and 
quadraplegics had a higher prevalence of pressure sore than incomplete lesions and paraplegics. The probable explanations are presented.

\section{RÉSUMÉ}

L'apparition fréquente d'escarres à la suite d'accident serieux de la moelle épinière a pu être démontrée à partir d'etudes effectuées sur 549 sujets ayant fait un séjour an Centre régional du Midwest pour les blessés de la moelle épinière (Midwest Regional Spinal Cord Injury Care Center) et ce entre 1973 et juin 1978. Les données traitées furent basées sur les entrées 'system' opposées aux entrées 'non-system', le niveau anatomique des blessures, les emplacements multiple ou simple, les blessures physiologiques complètes ou incomplètes, la présence d'escarres lors de l'admission ou leur développement pendant l'hospitalisation. Les résultats ont montré que les patients 'non-system' avaient une sensiblement plus haute prédisposition aux escarres dans toutes les catégories. Le niveay anatomique de la blessure aussi bien que l'état physiologique intact de la moelle épinière furent trouves comme étant les facteurs les plus importants dans cette prédisposition certaine. La région cervicale fut trouvée comme étant la plus haute prédisposition aux escarres aux emplacements simples ou multiples. Les lésions complètes, les quadriplégiques et paraplégiques avaient une plus haute prédisposition aux escarres que les lésions incomplètes. Les explications probables sont présentées.

\section{ZUSAMMENFASSUNG}

Die gegenwärtige Verbretung der Entwicklung von Druckstellen akuter Rückenmarksschäden wurde von 549 Patienten, die vom 'Midwest Regional Spinal Cord Injury Care Center' von 1973 bis zum Juni 1978 aufgencmmen wurden, bestätigt. Die gesammelten Tatsachen basierten auf einen systematischen gegen unsystematischen dem Aufnahme, anatomischen Grade von Schäden, mannigfaltigen oder einfachen Lage, vollständigen oder unvollständigen physiologischen Schäden und der Erscheinung von Druckstellen unter Aufnahme oder Entwicklung während der stationären Behandlung. Die Ergebnisse zeigten, daß unsystematische Patienten eine bedeutend größere Verbreitung von Druckstellen in allen Kategorien zeigten. Der Grad anatomischer Schäden sowie die physiologische Unversehrtheir des Rückenmarks wurden als die wichtigsten Faktoren in der gegenwärtigen Verbreitung ermittelt. Es wurde herausgefunden, daß die Nacken-Region die größte Verbreitung von Druckstellen an mannigfaltigen und einzelnen Lagen hat. Vollständige Wuden und Quadriplegics zeigten eine größere Verbreitung der Druckstellen als unvollständige Wunden and Paraplegics. Die wahrscheinlichen Erklärungen sind vorhanden.

\section{REFERENCES}

Campbell, R. M. (1946). Plastic surgery in the paraplegic patient. NY. State Med. F., 46, $2040-2046$.

Dietrick, R. B. \& Russi, S. (1958). Tabulation and review of autopsy findings in 55 paraplegics. $\mathcal{F} A M A, 66,4 \mathrm{I}-44$.

Dowling, A. S. (I970). Pressure sores-their cause, prevention, and treatment. $M d$. State Med. F., 19, I3 I-I 34 .

Edberg, E. L., Cerny, K. \& Stauffer, E. S. (1973). Prevention and treatment of pressure sores. Phys. Ther., 53, 246-252.

KenNedy, R. H. (1946). New viewpoint toward spinal cord injuries. Ann. Surg., 124, I057-IO62.

Kosiak, M. (1959). Etiology and pathology of ischemic ulcers. Arch. Phys. Med. Rehab., 40, 62-68.

KuHN, W. G. (1947). Care and rehabilitation of patients with injuries of spinal cord and cauda equina. f. Neurosurg., 4, 40-52.

MikULIC, M. A. (I977). Decubitus: an analysis of current methods of prevention and treatment. Arch. Phys. Med. Rehabil., 58, 516.

Munro, D. (1940). Care of back following spinal cord injuries. NEFM, 223, 39I-398.

PoER, D. H. (I946). Newer concepts in treatment of paralyzed patients due to wartime injuries of spinal cord. Ann. Surg., I23, 510-5I4. 
RugE, D. (1969). Spinal Cord Injuries. Springfield: Charles C. Thomas Publishers, first edition, I36-I37.

SheA, J. D. (1975). Pressure sores-classification and management. Clin. Orth., II2, 89-100.

Talbot, H. S. (1968). Pressure ulcers. Surg. Clin. N. Am., 48, 740-742. 